\title{
REPETITIVE PAROXYSMAL VENTRICULAR TACHYCARDIA
}

\author{
BY \\ J. P. P. STOCK \\ From the Stoke-on-Trent Hospital Group
}

Received September 15, 1961

Repetitive ventricular tachycardia is a relatively rare arrhythmia. The purpose of this paper is to describe four cases of this condition and to illustrate the potential value in a complex arrhythmia of studying long electrocardiographic records with the aid of statistical analysis. The first case showed features of such exceptional interest that it merits a detailed description.

Case 1. A man, aged 22, was first seen as an out-patient in May, 1958. He complained of dyspnœa on strenuous exertion but was able to lead a normal active life for a man of his age. He had never been conscious of palpitation. His heart action was known to have been irregular since childhood but otherwise he had had no relevant illness; no previous electrocardiogram had been recorded.

On clinical examination, apart from obesity (weight $15 \mathrm{st} .7 \mathrm{lb}$.; height $6 \mathrm{ft}$.) his general condition was excellent. The peripheral pulse was slow and irregular with an approximate rate of 24 a minute. Inspection of the neck revealed intermittent bouts of rapid irregular venous waves, each bout terminating in a precipitous y descent. On auscultation a gross arrhythmia was present which defied analysis. The blood pressure was approximately $140 / 85 \mathrm{~mm}$. Hg. There were no other clinical findings of note. A chest X-ray showed a large heart with a cardio-thoracic ratio of 60 per cent. Extracts from his first electrocardiogram are shown in Fig. 1. In view of these findings he was admitted to hospital where he stayed for one week. Quinidine sulphate $0.4 \mathrm{~g}$. t.d.s. immediately suppressed the arrhythmia and he remained in sinus rhythm for the next five weeks. It was then noted that although sinus rhythm was present when supine, numerous extrasystoles, often in runs, occurred on standing.

Six weeks after his discharge, the original arrhythmia had returned despite continuance of quinidine and he was re-admitted to hospital for further investigation. All therapy was omitted over a period of ten days while a number of investigations were carried out. Throughout this period the arrhythmia persisted day and night without intermission and without distress to the patient. Quinidine therapy was then restarted and sinus rhythm was again immediately restored. By the end of six weeks the cardio-thoracic ratio had fallen to 46 per cent, the cardiogram was physiological, and no evidence of structural heart disease could be found. He was again discharged from hospital to continue quinidine therapy as an out-patient.

During the next four months he was almost always found to be in sinus rhythm but repetitive runs of ectopic beats could usually be provoked by brisk exertion (e.g. jumping for one minute) and would persist for several minutes. In February 1959 quinidine was discontinued on account of side effects. After two to three months arrhythmia at rest reappeared but in less florid form. During the past two years he has been able to work regularly without medication despite the continued presence of the arrhythmia and a return of cardiac enlargement.

\section{Electrocardiogram}

Fig. 2 shows a continuous recording of lead II made in August 1958 and exemplifies the main features of the arrhythmia. It consists of repetitive runs of ectopic beats separated by either one or two sinus beats. Most paroxysms contain either four or five ectopic beats but their number may vary from one to twelve. The complexes were seen to have two distinct contours and it was this unusual finding that largely prompted a more detailed investigation. One type of complex dominates the paroxysms and is referred to as the " $\mathrm{Y}$ " ectopic. Approximately 40 per cent of all paroxysms consist of a run of four or five successive Y's. In well over half the paroxysms, however, 
this run of Y's is preceded by an ectopic beat of entirely different contour which is referred to as the " $\mathrm{X}$ " ectopic. Paroxysms commencing with an $\mathrm{X}$ are never preceded by more than one sinus beat. Although several thousand paroxysms have now been recorded, no exception to this rule has yet been encountered. In contrast, most paroxysms commencing with the $\mathrm{Y}$ complex are preceded by two sinus beats and a minority only by a single beat.

There can be no reasonable doubt that the $\mathrm{X}$ and $\mathrm{Y}$ complexes have different origins. Not only have they a completely different contour in every lead but the coupling time of the two ectopics to

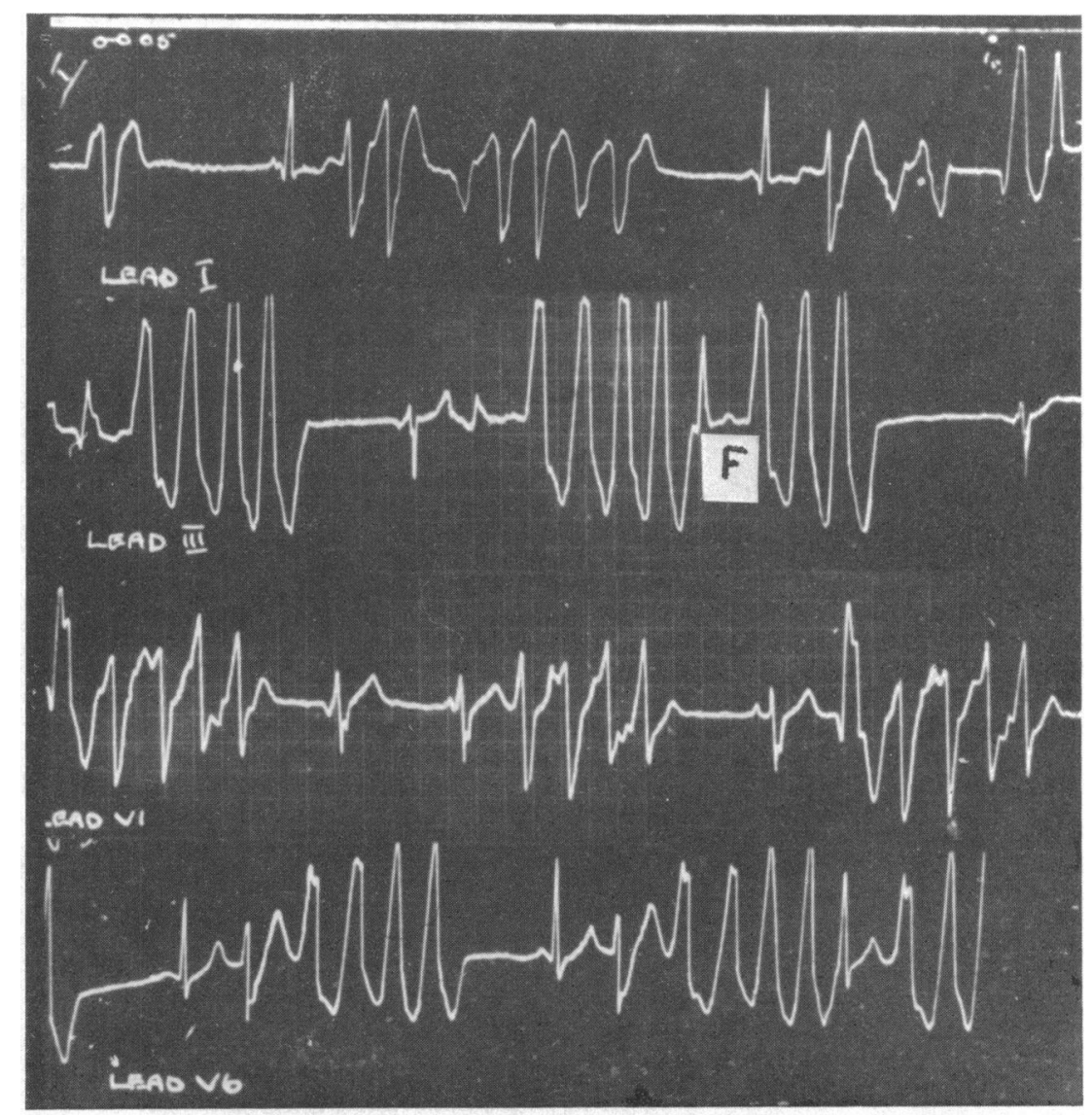

FIG. 1.-Case 1. Extracts from first electrocardiogram recorded in May 1958. $\mathrm{F}=$ Fusion beat occurring between two runs of $\mathrm{Y}$ ectopics.

the initiating sinus beat is consistently different; the coupling time of the Y ectopic to the initiating sinus beat is 0.36 to $0.38 \mathrm{sec}$. and that of the $\mathrm{X}$ ectopic is consistently $0.04 \mathrm{sec}$. longer. The frontal and horizontal plane projections of the vector loops of $\mathrm{X}$ and $\mathrm{Y}$ complexes further emphasize their essential difference (Fig. 3).

The ventricular origin of the $\mathrm{Y}$ variety is established by the frequent occurrence of fusion beats (Fig. 1). It is most probable that $\mathrm{X}$ is also ventricular for when it occurs as the commencing beat of a paroxysm its contour has remained constant in all records. This would be very unlikely if its wide contour were due to aberrant conduction of a supraventricular impulse. Complexes of a supraventricular impulse. Complexes 
resembling $\mathrm{X}$ occur commonly in the middle of longer paroxysms but in these instances their origin cannot be determined with certainty (Fig. 2, paroxysm 2).

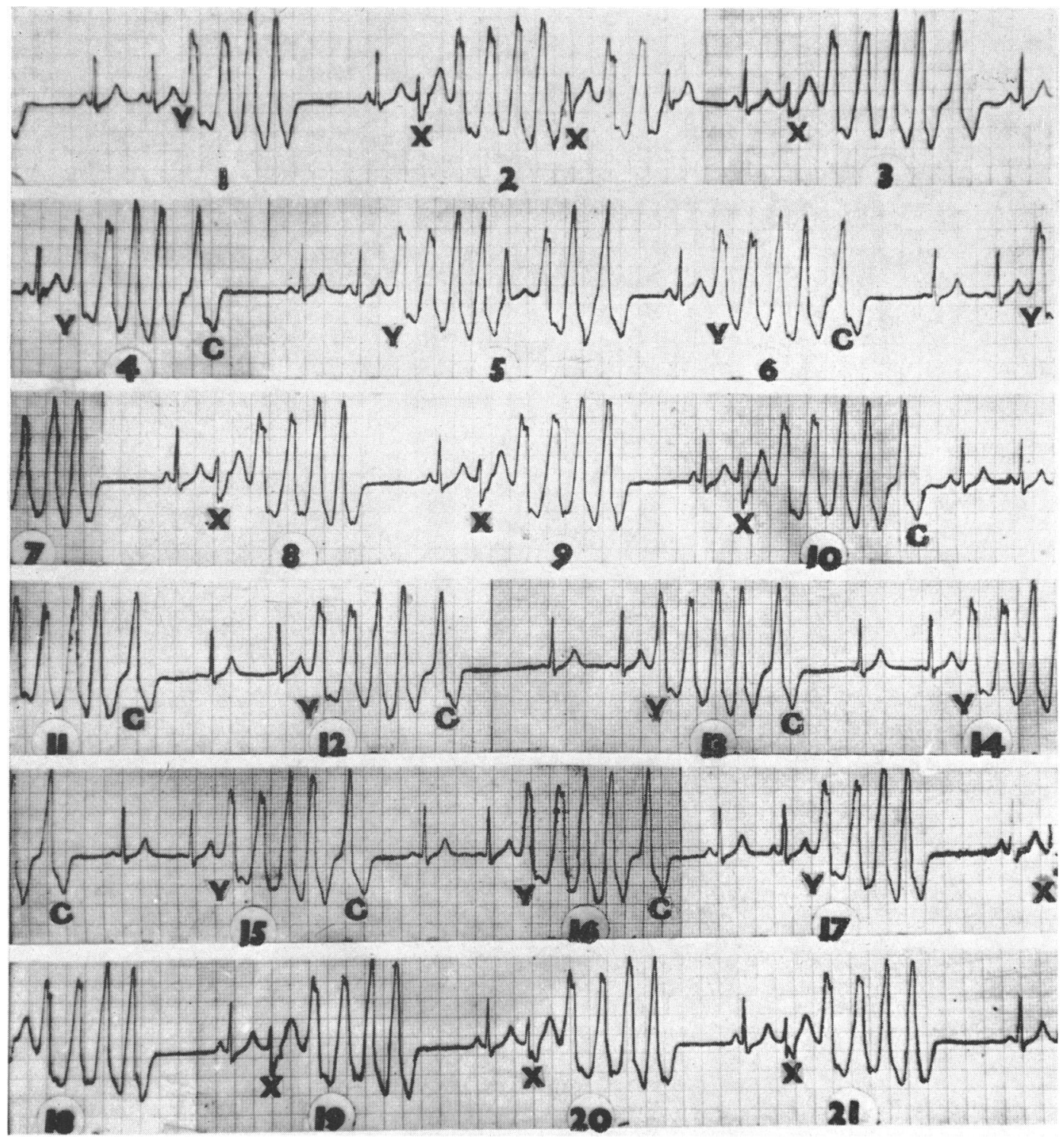

Fig. 2.-Case 1. Lead II. Continuous record of 21 paroxysms. $\mathrm{Y}$ and $\mathrm{X}$ denote the type of ectopic beat that initiates the paroxysm. $\mathrm{C}=$ terminal $\mathrm{C}$ ectopic.

It will be seen from Fig. 1 that the $Y$ ectopic has a mainly negative deflection in lead $I$ and a mainly positive deflection in lead V6. The explanation of this apparent anomaly was obtained by recording multiple unipolar chest leads in a symmetrical pattern from the first intercostal space to the mid-epigastrium. This showed that the null pathway on the body surface for the Y ectopic runs from the mid axilla on each side downwards across the xiphisternum. Leads recorded from above this line give mainly negative deflections and leads from below mainly positive deflections. 


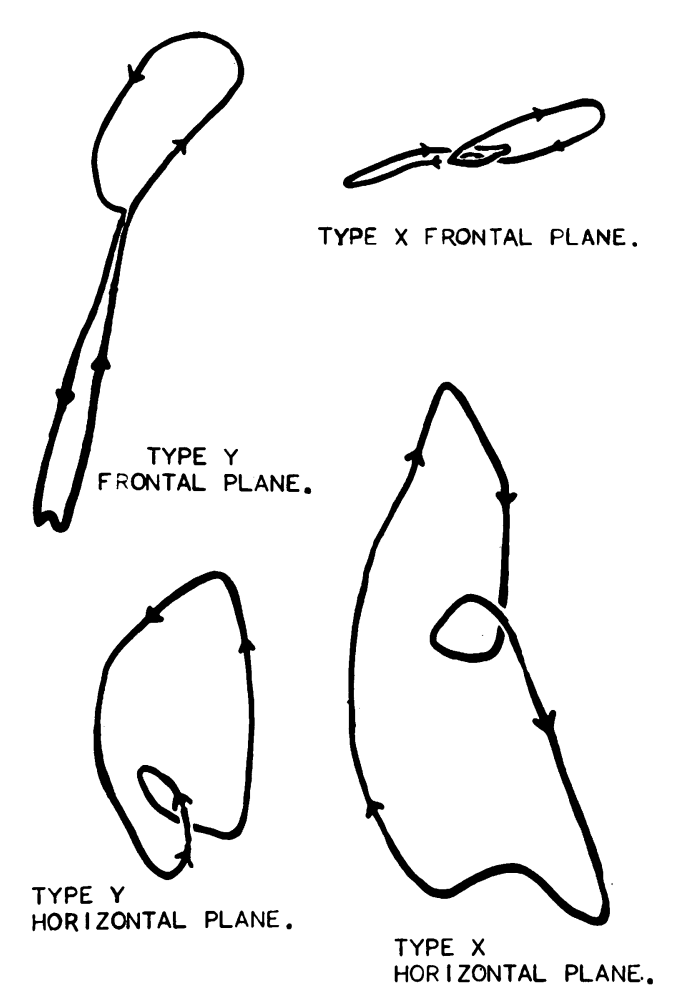

Fig. 3.-Frontal and horizontal plane projections of the vector loops of $X$ and $Y$. The frontal plane loops were constructed from a simultaneous recording of leads I and AVF at a paper speed of $50 \mathrm{~mm}$. per sec. The horizontal plane loops were similarly constructed from leads V1 and V4.
In attempting to analyse the arrhythmia it seemed important first to discover if any factors could be identified that could determine whether a paroxysm commenced with an $\mathrm{X}$ or $\mathrm{Y}$ ectopic. A notable feature of the arrhythmia is the wide variation in length of the postparoxysmal pauses and it was found that the longer pauses were generally followed by paroxysms commencing with an $\mathrm{X}$ ectopic whereas short pauses were followed by paroxysms commencing with a $\mathrm{Y}$ ectopic(Fig. 2). So many exceptions to this general rule occurred, however, that it was clearly necessary to study a very long recording which could be subjected to statistical analysis.

A long recording lasting twenty-four minutes had been made of the six limb leads and the six unipolar chest leads in immediate sequence followed by a further long record of lead II. This recording contains 464 paroxysms. Two hundred and forty-five of the paroxysms started with an X ectopic and these were preceded by only one sinus beat. The remaining 219 paroxysms commencing with a Y ectopic may be subdivided into 172 that were preceded by two sinus beats and 47 preceded by only one. Thus there are three main paroxysm patterns and in the interest of brevity it is convenient to refer to them as $X$ paroxysms, $2 Y$ paroxysms and 1Y paroxysms respectively (Table I).

TABLE I

FReQuency OF X, 2Y AND 1Y PAROXYSMS IN A 24-Minute ReCoRding

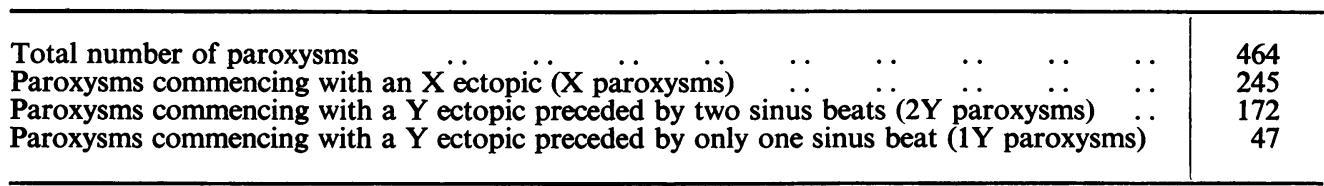

All the post-paroxysmal pauses were measured from the junction of the final deflection of the last ectopic with the iso-electric line to the commencement of the succeeding sinus $\mathrm{P}$ wave. They may be divided into three groups, namely pauses preceding $1 \mathrm{Y}, 2 \mathrm{Y}$, and $\mathrm{X}$ paroxysms respectively. The mean values for the lengths of each group of pauses is shown in Table II, in 1/100's second.

Analysis of variance revealed that the differences of the mean values of the pause lengths in the three groups were highly significant. This finding establishes a clear relationship between the length of the post-paroxysmal pause and the events that immediately follow it. Thus a short pause is usually followed by a single sinus beat and a Y paroxysm, a long pause by a single sinus beat and an 
TABLE II

Analysis of Post-Paroxysmal Pause Lengths in $\frac{1}{100}$ Second

\begin{tabular}{|c|c|c|c|c|}
\hline & & & Mean values & $\begin{array}{c}\text { Significance of } \\
\text { difference }\end{array}$ \\
\hline Pauses preceding $1 \mathrm{Y}$ paroxysms (1Y pauses) & . & . & $20 \cdot 7$ & \multirow{3}{*}{$\begin{array}{l}\mathrm{P}<0.001 \\
\mathrm{P}<0.01\end{array}$} \\
\hline Pauses preceding $2 \mathrm{Y}$ paroxysms (2Y pauses) & .. & . & $48 \cdot 76$ & \\
\hline Pauses preceding $\mathrm{X}$ paroxysms ( $\mathrm{X}$ pauses) & . & . & $63 \cdot 23$ & \\
\hline
\end{tabular}

$\mathrm{X}$ paroxysm, and pauses of intermediate length by two sinus beats and then a $\mathrm{Y}$ paroxysm. Further study revealed a second factor that selectively favours the appearance of $2 \mathrm{Y}$ paroxysms and accounts for most of the exceptions to this "pause rule."

In the record under consideration, a fundamental unit in the majority of the paroxysms consists of a run of four successive $Y$ ectopics with progressive shortening of the cycle length (see Fig. 2, paroxysm 1). The interval between the first two $\mathrm{Y}$ ectopics is fairly constantly 0.38 sec., whether they are preceded by an X ectopic or not. The interval between the second and third Y's is $0.3 \mathrm{sec}$. and between the third and fourth $0.26 \mathrm{sec}$. In this basic Y quartet the second pair of Y's differ slightly but distinctly in contour from the first pair. The difference is most pronounced in right præcordial leads (see lead V1 in Fig. 1). When five successive Y ectopics occur, in the majority of instances the fifth $\mathrm{Y}$ is separated from the basic quartet by a short but distinct interval. Typical examples of this "tail end" ectopic are shown in Fig. 2, and since it appears to play an important role in the mechanism of the arrhythmia it is convenient to give it a separate designation the " $C$ " ectopic. This $\mathrm{C}$ ectopic can be readily identified in each of the twelve leads except lead $\mathrm{I}$ and its contour is intermediate between that of the first and the second pair of a Y quartet from which it is separated by a distinct interval. In the limb leads this interval is not iso-electric until its point of junction with the $\mathrm{C}$ ectopic which is always on the iso-electric line. In the record under consideration, lead I contained 57 paroxysms, and since the $\mathrm{C}$ ectopic cannot be identified for certain in this lead, these 57 paroxysms must be excluded. One hundred and twenty-three of the remaining 407 paroxysms ended with a $\mathrm{C}$ ectopic and, with only one exception, all were followed by a $2 \mathrm{Y}$ paroxysm, whatever the length of the intervening pause. The $\mathrm{C}$ ectopic thus appears to prevent the appearance of an $\mathrm{X}$ ectopic following the next sinus beat.

The scattergram in Fig. 4 shows the lengths of the post-paroxysmal pauses divided into three groups. The central column shows pauses before all paroxysms commencing with an $\mathrm{X}$ ectopic. The left-hand column shows the pauses before $Y$ paroxysms when the preceding paroxysm had not ended with a $\mathrm{C}$ ectopic. It will be seen that in the absence of the $\mathrm{C}$ ectopic, the "pause rule", while not absolute, has few exceptions. Both groups of pauses, moreover, have a substantially normal distribution. The right-hand column of the scattergram shows the pauses before $\mathbf{Y}$ paroxysms, when the preceding paroxysms had ended with a C ectopic. The lengths of these pauses are distributed fairly evenly throughout the range and it therefore seems clear that two separate and apparently unrelated rules determine how a paroxysm will commence.

The mutual antagonism between the $C$ ectopic and the $X$ variety is well shown in Fig. 5 . The number of $\mathrm{C}$ ectopics and the number of $\mathrm{X}$ ectopics in every twenty paroxysms throughout the record have been plotted sequentially. A virtually perfect negative correlation is shown between the incidence of $C$ and $X$. There is, moreover, an interesting cyclical variation over every 100 to 120 paroxysms corresponding to a time interval of approximately six minutes.

A postural factor was also observed for, when the electrocardiogram was recorded with the patient standing, the $\mathrm{X}$ variety of ectopic beat never appeared. 
LENGTH OF PAUSE

BEFORE Y PAROXYSNS

WITH NO PRECED ING

SECONDS.

C ECTOPIC.

0.9

0.8

0.7

0.6

0.5

$\times$

0.4

$x x$

$x$

$x x$

$x x$
$x x$

0.3

$x x$

$x$

$x$
$x \times$
$x$

$x$

0.2

$x$

$x$

$x x x x x x x x x x x x$

$x \times x$

$x \times x \times x$
LENGTH OF PAUSE

BEFORE ALL $X$

PAROXYSMS.

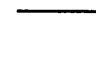

$x$

$x$

$x$
$x$

$x \times x \times x$

$x \times x \times x \times$

$x \times x$

$x \times x \times$

$x x$

$x \times x \times x$

$x \times x \times x \times x \times x \times x \times x$

$x x$

$x \times x \times x \times x \times x \times x$

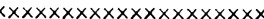

$x \times x \times x \times x \times x \times x \times x \times x \times x x$ $x \times$

$x \times x \times x \times x \times x \times x \times x \times x \times x \times x \times x \times x \times x \times x$

$x \times x$

$x \times x \times x \times x x$

$$
x x
$$

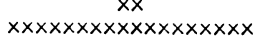

$x \times x$

$x \times x \times x \times x \times x \times x$

$x \times x x$

$x \times x \times x \times x \times x \times x$

$x$

$x$

$x \times x$

$x \times x$

$x \times x$

$x x$

$x \times x$

$x x$

$x x$

$x \times$

$x$

$\times$

$x$
LENGTH OF PAUSE

BEF ORE Y PAROXYSMS

FOLLOWING C

ECTOPIC.

$x$

$x$

$x \times x \times x$

$x$

$x \times x$

$x \times x$
$x$

$x \times x$

$x \times x x$

$x x$

$x \times x \times x$

$x \times x$

$x \times$
$x$

$x \times x \times x$

$x \times x \times x$
$x x$
$x$

$x \times x \times$

$x, x x$

$x$

$x \times x x$

$x x$

$x \times x x$

$x \times x$

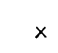

$x \times x$

$x \times x x$

$x x$

$x_{x \times x \times x}$ $x \times x \times x \times x \times x \times x x$

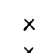

$x$

$x \times x x$

$x x$

$x \times x$

$x \times x \times x x$

$x \times x$

$x \times x x$

$x$

$x$

0.1

$x$

$x x x x$

$x x$

0.0

$x x$

Fig. 4.-Scattergram of lengths of post-paroxysmal pauses. 


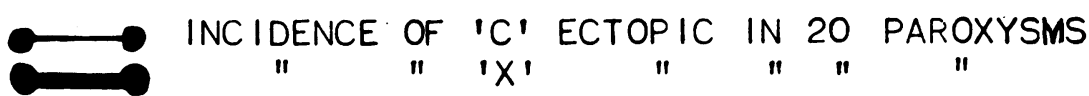

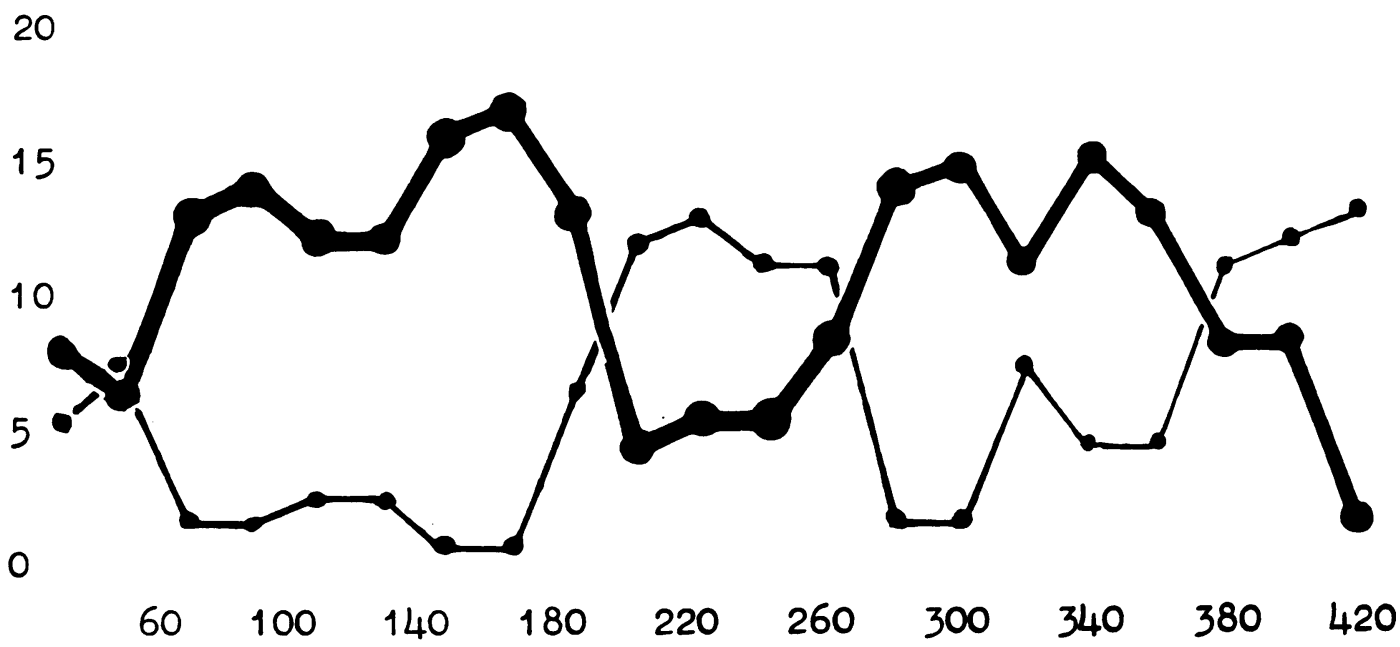

FIG. 5.-Graph showing incidence of $\mathrm{C}$ ectopic and $\mathrm{X}$ ectopic in each successive 20 paroxysms.

\section{Number of Ectopics in each Paroxysm}

It will be seen in Table III that paroxysms commencing with an X ectopic and followed by four Y's were almost twice as common as any other pattern. Only 28 paroxysms contained between seven and twelve ectopic beats and with one exception these longer paroxysms appeared to consist of two shorter ones connected by a linking complex. These "linking complexes" appeared to be either reciprocal beats or ectopic beats resembling the $\mathrm{X}$ variety. Two examples are shown in Fig. 2 (paroxysms 2 and 5).

TABLE III

Frequency Distribution of The Number of Ectopics in EACH of the Three Main Groups of PAROXYSMS

\begin{tabular}{|c|c|c|c|c|c|c|c|c|c|c|c|c|c|c|}
\hline & & \multicolumn{12}{|c|}{ Number of ectopics } & \multirow{2}{*}{ Tota } \\
\hline & & 1 & 2 & 3 & 4 & 5 & 6 & 7 & 8 & 9 & 10 & 11 & 12 & \\
\hline $\begin{array}{l}\text { 1Y paroxysms No. } \\
2 Y \text { paroxysms No. } \\
\text { X paroxysms No. . }\end{array}$ & $\begin{array}{l}. \\
\cdots\end{array}$ & $\begin{array}{l}0 \\
0 \\
2\end{array}$ & $\begin{array}{l}2 \\
0 \\
3\end{array}$ & $\begin{array}{l}\mathbf{1} \\
\mathbf{0} \\
\mathbf{0}\end{array}$ & $\begin{array}{r}25 \\
72 \\
8\end{array}$ & $\begin{array}{r}17 \\
89 \\
164\end{array}$ & $\begin{array}{r}0 \\
6 \\
47\end{array}$ & $\begin{array}{l}0 \\
0 \\
4\end{array}$ & $\begin{array}{l}1 \\
3 \\
0\end{array}$ & $\begin{array}{l}0 \\
2 \\
8\end{array}$ & $\begin{array}{l}1 \\
0 \\
6\end{array}$ & $\begin{array}{l}0 \\
0 \\
1\end{array}$ & $\begin{array}{l}\mathbf{0} \\
0 \\
2\end{array}$ & $\begin{array}{r}47 \\
172 \\
245\end{array}$ \\
\hline Total & . & 2 & 3 & 1 & 105 & 270 & 53 & 4 & 4 & 10 & 7 & 1 & 2 & 464 \\
\hline
\end{tabular}

It seemed worth while to enquire if the length of the post-paroxysmal pause bore any relation to the number of ectopics in the paroxysm that followed. It was found that the pause lengths preceding X paroxysms bore no relation to the number of ectopics they contained. The mean value for the pauses preceding $2 \mathrm{Y}$ paroxysms was significantly longer when the paroxysms contained six ectopics $(0.61 \mathrm{sec}$.) than when it contained either four or five $(0.47 \mathrm{sec}$., $\mathrm{P}<0.01)$. Furthermore, the number of ectopics in a $1 Y$ paroxysm was very significantly related to the preceding pause. The 
mean length of the pauses preceding those with five ectopics was $0.27 \mathrm{sec}$. and of those with four ectopics $0.14 \mathrm{sec}$. (significance of difference $\mathrm{P}<0.01$ ). It seems clear, however, that other factors must be involved and that the number of ectopics in a paroxysm has only a limited relationship to the length of the preceding pause.

\section{Variation of Pause Length}

Since the length of the post-paroxysmal pause plays so important a part in determining the paroxysm pattern that follows (Table II), it is necessary to consider the factors responsible for its variable duration. If the sinus node continues to discharge undisturbed during a paroxysm, the post-paroxysmal pause should be compensatory. Under these circumstances, if the sinus rate is constant, it should be possible to predict when the next sinus beat should occur after the end of a paroxysm. In the present case, there is a considerable sinus arrhythmia, adjacent measurable sinus cycles often varying by $0.1 \mathrm{sec}$. or more. This necessarily introduces a prohibitive error into attempts to ascertain from the length of the post-paroxysmal pause whether any shift in sinus rhythm has occurred during a paroxysm. Nevertheless, pauses of far greater length were observed than could be explained by variations in the sinus rate alone. The assumption that this was attributable to retrograde conduction of the last ectopic beat to the atrium is supported by recordings made when the pause followed only one extrasystole. This is illustrated in Fig. 6. The strip begins with three

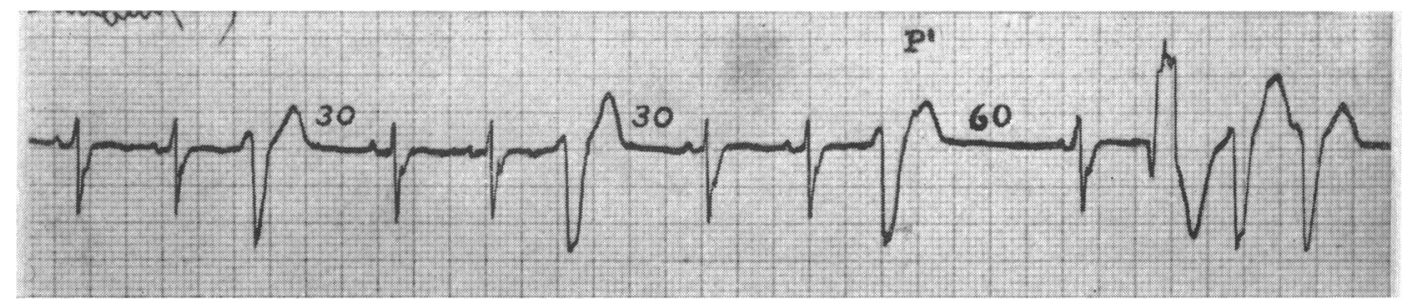

FrG. 6.-Case 1. Lead V1 showing lengthening of post-paroxysmal pause following retrograde conduction of ectopic impulse to atria.

groups of two sinus beats each followed by a single $\mathrm{Y}$ ectopic. The pauses following the first two $\mathrm{Y}$ ectopics are compensatory. A notch is present on the $\mathrm{T}$ wave of the third $\mathrm{Y}$ ectopic which is not present on the preceding two and which is highly suggestive of a $\mathrm{P}$ wave indicative of retrograde conduction of the ectopic stimulus to the atrium. The long pause that follows may be attributed to discharge and depression of the S-A node by the retrograde impulse. In conformity with the "pause rule," this long pause is followed by a single sinus beat and an X ectopic. An csophageal lead was recorded in view of the accepted value of these leads in disturbances of atrial rhythm but owing to great variation in the contour of the sinus $\mathbf{P}$ wave, it did not prove helpful.

Further evidence of the effect of retrograde conduction on the subsequent pause length was obtained from reciprocal beats. In Fig. 7, for example, a typical X paroxysm ends with a complex of almost normal contour. No preceding $P$ wave is visible but this beat cannot be sinus in origin for the R-R interval between it and the next sinus beat is one second and no sinus cycle approaching this length occurs anywhere else in the record.

\section{Follow-up Electrocardiographic Studies}

Electrocardiograms have been recorded monthly over the past two years. The $\mathrm{C}$ ectopic has never re-appeared but the "pause rule" still operates in determining whether a paroxysm will commence with an X or a Y ectopic. Even when the "paroxysms" consist of only single ectopics the general structure of the arrhythmia remains the same, $X$ ectopics never being preceded by more than 


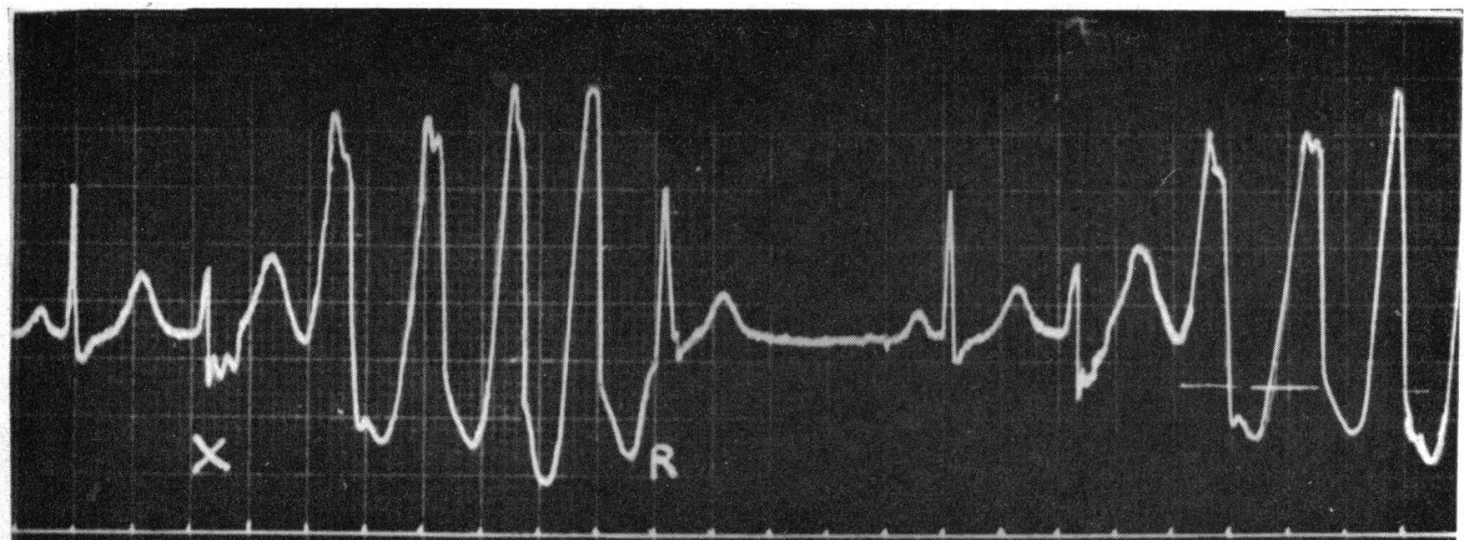

Fig. 7. -Example of reciprocal beat $-R . \quad X=X$ variety of ectopic.

one sinus beat and $\mathrm{Y}$ ectopics by either one or two. During the past twelve months the average number of ectopics in each paroxysm has shown a further decline.

A point of considerable theoretical interest is that as the number of ectopics in each paroxysm has become less, the coupling time of both varieties of ectopic beat has increased. In any given recording with the patient at rest, the coupling time of different paroxysms to the initiating sinus beat never varies by more than $0.03 \mathrm{sec}$. Such minor variations, moreover, bear no relationship to the number of ectopics in individual paroxysms. Examination of tracings recorded at different times, however, reveals a clear relation between the mean coupling time and the average number of ectopics in each paroxysm. The findings for the Y ectopic from ten different records are shown graphically in Fig. 8. The mean coupling time of twenty $Y$ paroxysms is plotted against the average number of ectopics they contained. The patient was not receiving any drug therapy at the time the recordings were made. The initial deflection of the Y ectopic follows immediately after the end of the $T$ wave and the variations in coupling times are therefore due to variations in the Q-T interval. Since the Q-T interval is inversely related to the heart rate, the lengthening of the coupling time which has occurred as the number of ectopics in each paroxysm has declined may simply be an

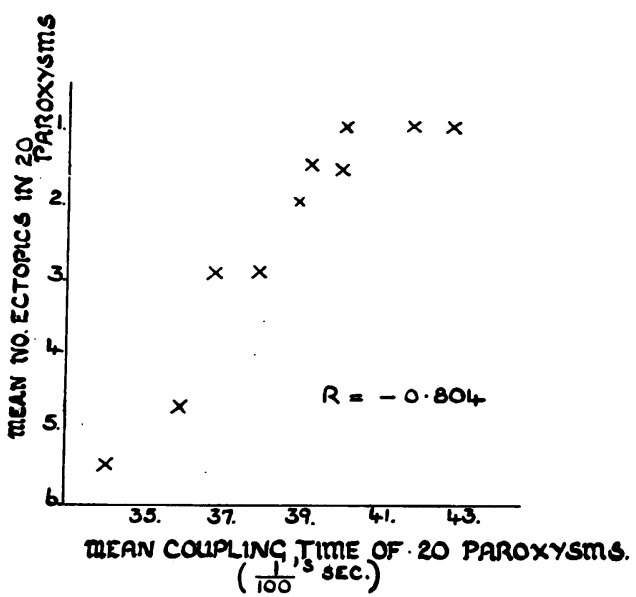

Fig. 8.-Scattergram to show relation between coupling time of $Y$ ectopic to initiating sinus beat and the average number of ectopics in each paroxysm in 10 different recordings. expression of a lengthened Q-T interval due to a slower average ventricular rate. The illustrations of the case published by Berard (1931) seem to show the same phenomenon. This observation is incompatible with the re-entry theory of extrasystoles for, as pointed out by Scherf and Schott (1959), with a slower ventricular rate due to a reduction in the number of ectopic beats, a shortening, not a lengthening, of the coupling time would be expected. 


\section{Hamodynamic Data}

A limited cardiac catheterization was carried out; the cardiac output was $3.81 . / \mathrm{min}$. (Cardiac index $1.751 . / \mathrm{min}$.).

Extracts from an arterial pressure curve recorded at this time are illustrated in Fig. 9. The mean arterial pressure falls progressively during a paroxysm, the downward slope of the curve
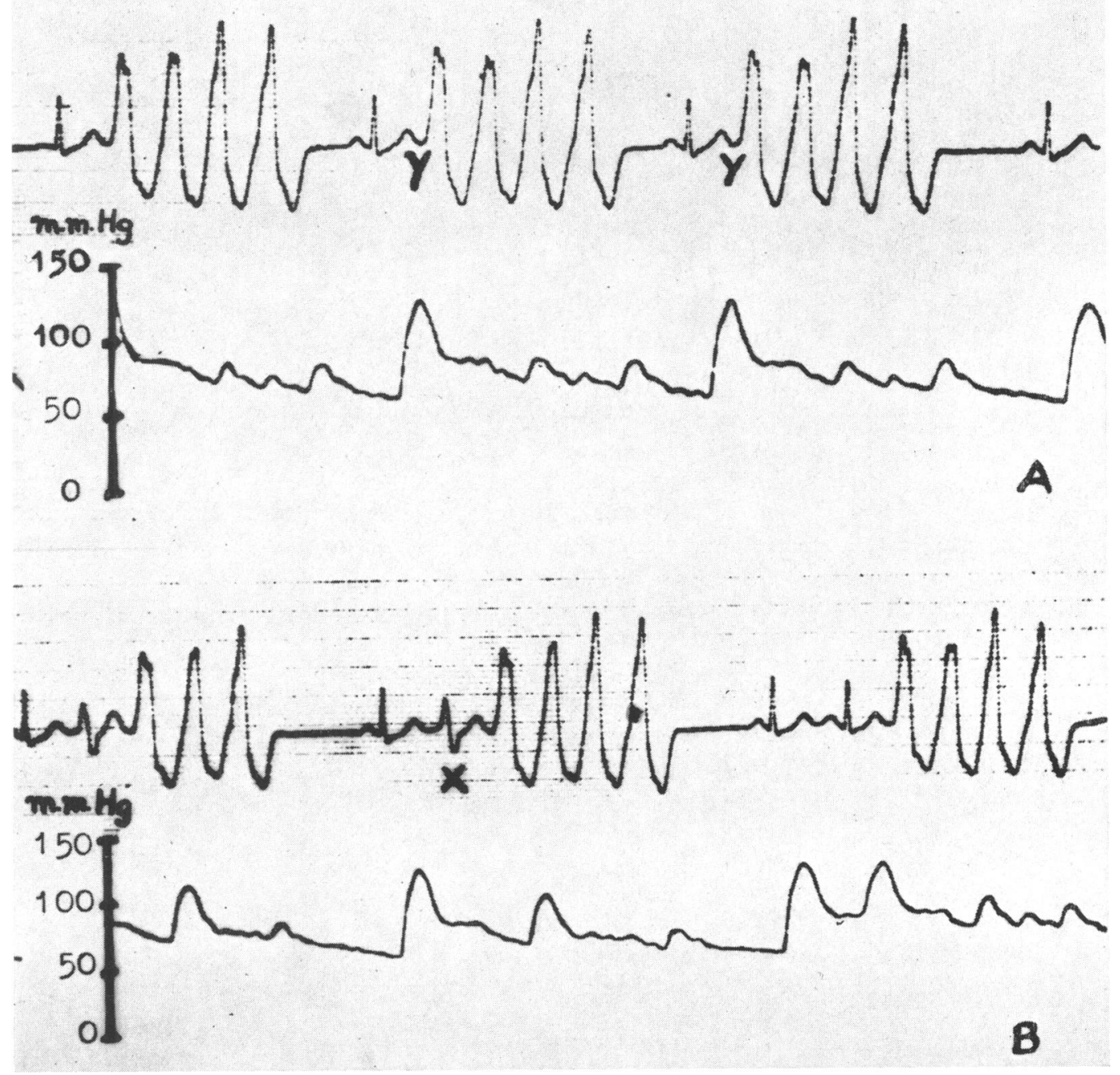

FIG. 9.-Case 1. Simultaneous lead II electrocardiogram and direct right brachial artery pressure record during (A) $Y$ paroxysms and (B) $X$ paroxysms.

being interrupted by ripples due to the ectopic beats. When the paroxysm commences with a $Y$ ectopic (Fig. 9A), the second and fourth beats of the usual Y quartet produce appreciably larger pulse waves than the first and third, a form of pulsus alternans. On the other hand, when the paroxysm commences with $\mathrm{X}$, the first $\mathrm{Y}$ ectopic of the quartet is dynamically almost equivalent to a sinus beat (Fig. 9B), the $\mathrm{X}$ ectopic producing no apparent pulse wave. The recording was made over five minutes and this behaviour of the pulse contour remained consistent throughout, so that the occur- 
rence of an X ectopic beat could always be recognized immediately from the pressure trace alone. The reason the $\mathrm{X}$ ectopic so materially increases the dynamic effect of the first $\mathrm{Y}$ that follows it is presumably due to increased left ventricular filling, but since it is impossible to measure left ventricular diastole in the tracing the precise mechanism must remain speculative.

Case 2. A man, aged 60, was first seen as an out-patient in January, 1959 with a history of a fluttering sensation in the præcordium and tightness in the chest on exertion for two and a half months. The symptoms were more alarming than disabling to the patient. His past medical history was irrelevant. Apart from gross arrhythmia, clinical examination was negative. His blood pressure was $130 / 90 \mathrm{~mm}$. $\mathrm{Hg}$ and his chest $\mathrm{X}$-ray showed a normal cardiovascular outline.

Electrocardiogram. This showed repetitive runs of ventricular ectopic beats separated by either one, two, or occasionally three sinus beats. A long recording of each of the twelve routine leads was made for analysis: this contains 221 paroxysms. Fig. 10 shows a characteristic extract from

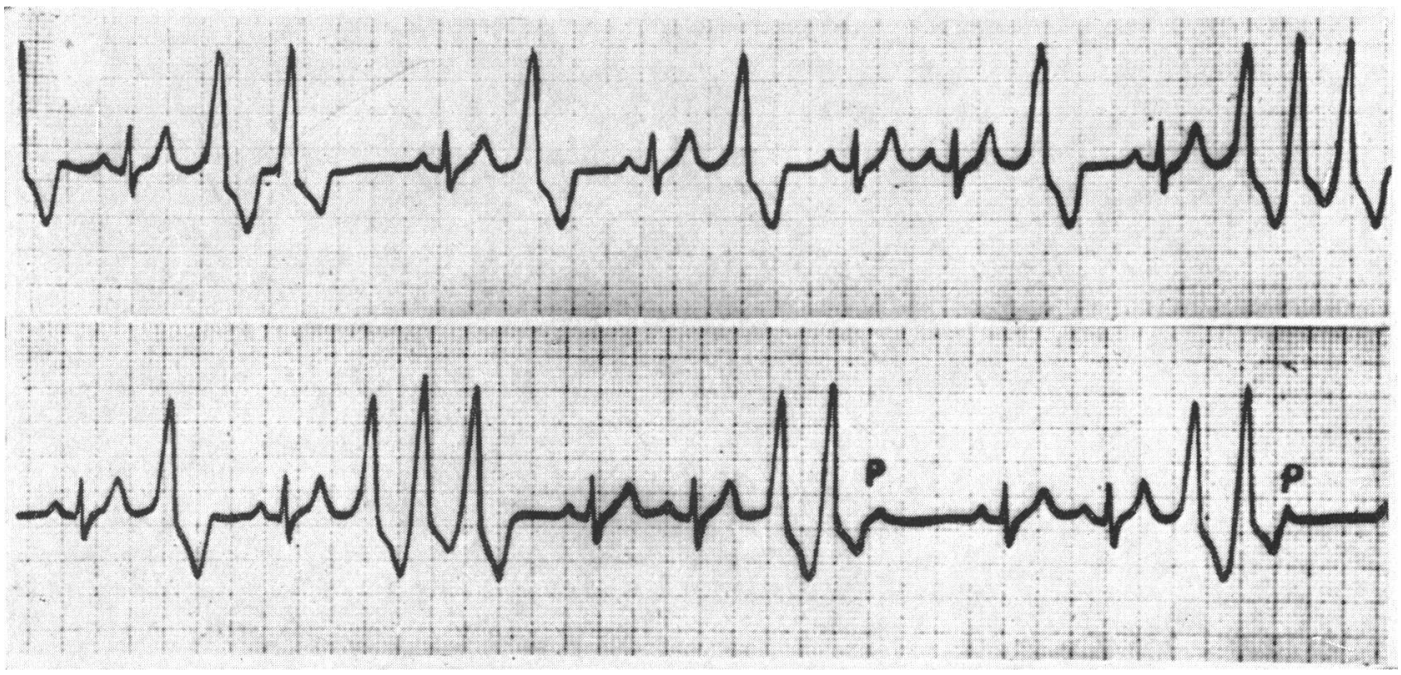

FIG. 10.-Case 2. Lead II showing repetitive $\mathrm{Y}$ paroxysms. $\mathbf{P}=$ blocked sinus $\mathbf{P}$ wave.

lead II. Only one ectopic focus is present and its contour is virtually identical with the Y ectopic of Case 1, having a deflection that is directed mainly downwards in lead I and upwards in leads V5 and V6. The coupling of the first ectopic of each paroxysm to the preceding sinus beat is constantly $0.44 \mathrm{sec}$. The arrhythmia is clearly much simpler than that of Case 1 . The number of ectopics in each paroxysm of the whole record varies from 1 to 4 . Retrograde conduction of the ectopic stimulus to the atrium does not seem to occur for all the post-paroxysmal pauses are compensatory, being within $0.04 \mathrm{sec}$. of the length predicted from the length of the sinus cycle and the duration of the paroxysm. There is, moreover, no evidence that the length of the post-paroxysmal pause bears any relation either to the number of succeeding sinus beats or the number of ectopic beats in the next paroxysm.

This record nevertheless conforms to certain "rules." There is a clear-cut inverse relationship between the number of sinus beats preceding the paroxysm and the number of ectopics it contains. Fifty-one of the 221 paroxysms contain three ectopics and 5 contain four ectopics; these 56 paroxysms were all preceded by only one sinus beat. Conversely three successive sinus beats occurred on 9 occasions and four on 2 occasions, and these were all followed by a single ectopic beat. The mean number of ectopics in paroxysms following single sinus beats was 2.05 and of those following two sinus beats was $1 \cdot 1$ (significance of difference $P<0 \cdot 001$ ). 
Paroxysms containing three ectopic beats appear to influence the events that follow them. In 43 of the 51 paroxysms with three ectopics the pattern that follows is known, and in $34(79 \%)$ it consists of two sinus beats and a single ectopic.

When the paroxysm contains two ectopic beats the cycle length appears to be determined by the number of preceding sinus beats. Following a single sinus beat the cycle length is 0.44 sec., and following two sinus beats it is $\mathbf{0 \cdot 3 4} \mathrm{sec}$. With the shorter cycle length the second ectopic terminates in either a blocked sinus $P$ wave (paroxysms 8 and 9, Fig. 10) or a sinus beat with a greatly prolonged P-R interval. This strongly suggests that concealed retrograde conduction (Langendorf, 1948) has occurred, rendering the A-V junction absolutely or partially refractory.

No further study of this patient's arrhythmia was possible for at his next and all subsequent attendances he was found to be in regular sinus rhythm. It is of interest that up till eight years before he was seen the patient had been smoking 25 cigarettes daily. He then stopped smoking but had re-started two and a half months previously and had noticed that the onset of his symptoms coincided with this. The day after this recording was made he again stopped smoking of his own accord, since when the arrhythmia has not recurred.

Comment. Both these cases showed gross ventricular arrhythmia yet in neither was there evidence of underlying structural heart disease. However, in the following two cases with known organic heart disease, a closely similar electrocardiographic pattern was seen, and it appeared to have a more sinister import.

Case 3. A woman, aged 55, was referred to hospital in April, 1960 following a transient left hemiparesis and was found to have an irregular heart action due to frequent ventricular extrasystoles. She had noted some dyspnoa, tightness in the chest, and palpitation on exertion for six months. Clinical examination revealed cardiac enlargement, bigeminal heart action, and an apical diastolic gallop. Her blood pressure was $220 / 120 \mathrm{~mm}$. Hg. A chest X-ray showed a c.t.r. of 62 per cent with selective left ventricular enlargement.

Electrocardiogram. This showed a mean electrical axis of $-20^{\circ}$ with left ventricular hypertrophy and stress in the præcordial leads. The resting record showed ventricular extrasystoles occurring for the most part regularly after every sinus beat with a fixed coupling of $0.36 \mathrm{sec}$. While the majority of the extrasystoles occurred singly, there were occasional runs of three or four in succession. The contour of the extrasystoles was again similar to the $Y$ ectopic of Case 1 with a mainly downward deflection in lead I and an upward deflection in leads V5 and V6. On the lightest exertion (e.g. raising the legs with knees extended) the typical pattern of repetitive ventricular tachycardia would appear (Fig. 11A). In general the runs of ventricular tachycardia were separated from each other by single sinus beats but occasionally two or three sinus beats intervened. The number of ectopics in each paroxysm varied from one to six, being most commonly three or five. The first ectopic of the majority of the paroxysms had a fixed coupling of $0.32 \mathrm{sec}$. to the preceding sinus beati.e. $0.04 \mathrm{sec}$. shorter than the coupling of the single ectopics in the resting record. Occasionally, however, a paroxysm commenced with one or more fusion beats, sinus rhythm merging into a run of ventricular tachycardia. Fig. 11B shows a typical example of this in a simultaneous recording of lead II and an osophageal lead made immediately following a brief period of leg raising. The extract commences with two sinus beats followed by a paroxysm with the usual coupling time of $0.32 \mathrm{sec}$. Two sinus beats each succeeded by single extrasystoles also with coupling times of $0.32 \mathrm{sec}$. follow. There is then a normal sinus beat followed by two fusion beats and three ventricular ectopics. Paroxysm 1 contains five ectopics and its duration is $1.84 \mathrm{sec}$; if the fusion beats are included, paroxysm 2 also contains five ectopic beats and its duration is also $1.84 \mathrm{sec}$. This finding suggests that in this case the ectopic focus is occasionally capable of automatic impulse formation.

The patient was given quinidine but she died suddenly 36 hours later. No autopsy could be obtained.

Case 4. A man, aged 67, was seen at his home in June, 1958. He gave a history of hypertensive heart disease with recurrent episodes of left ventricular failure over the previous three years. He was in mild 

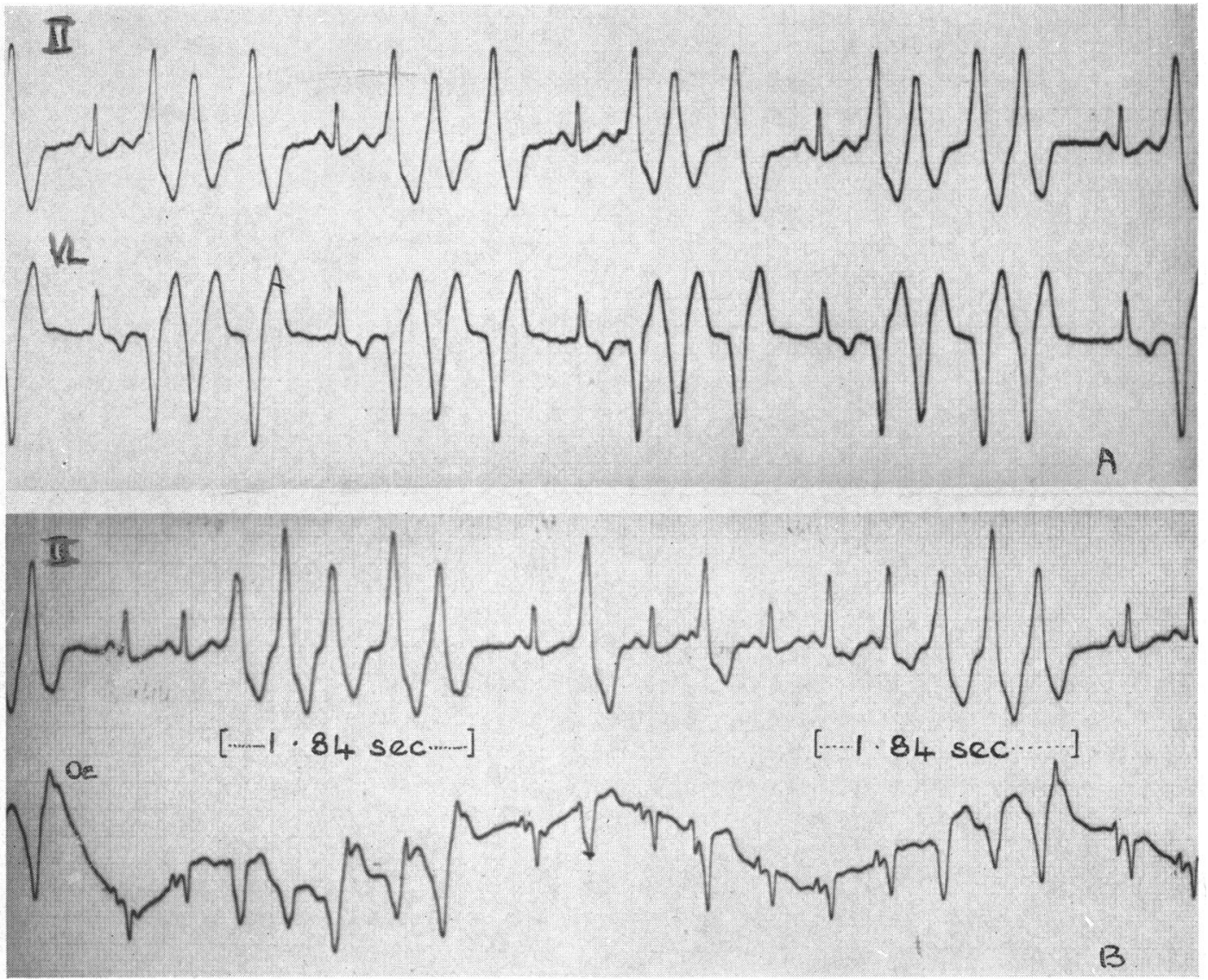

Fig. 11.-Case 3. (A) Simultaneous recording of leads II and AVL after light exercise. (B) Simultaneous recording of lead II and an osophageal lead after light exercise. For further description see text.

congestive failure with the apex beat in the sixth intercostal space $2.5 \mathrm{~cm}$. beyond the mid-clavicular line. The most striking clinical finding was gross arrhythmia. B.P. 190/120 mm. Hg (approximately).

Electrocardiogram. This showed a mean electrical axis of $-30^{\circ}$ and left ventricular hypertrophy and "stress" in the præcordial leads. Sinus rhythm was present but was constantly interrupted by runs of ventricular tachycardia and also by isolated extrasystoles. The contour of the extrasystoles differed from that in the preceding three cases in that it showed a mainly positive deflection in lead $I$. The number of ectopics in each paroxysm of tachycardia varied from two to eight (Fig. 12). It will be seen that the first ectopic beat of each paroxysm differs slightly in outline from the remainder

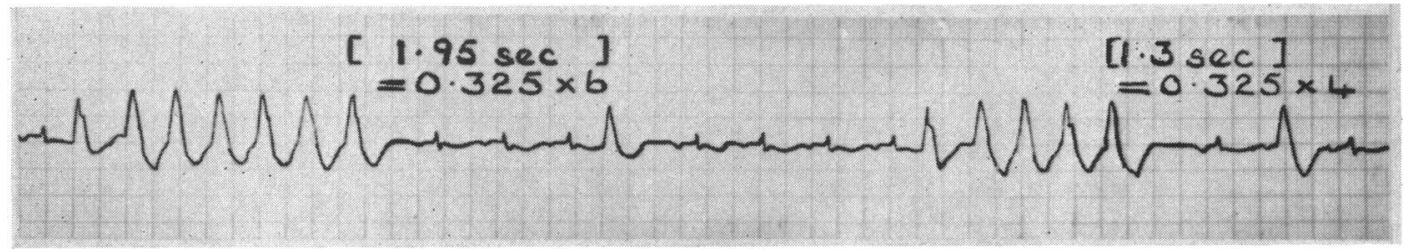

Fig. 12.-Case 4. Lead II. The coupling time of the first ectopic to the preceding sinus beat in both paroxysms is $0.24 \mathrm{sec}$. The coupling time of the isolated extrasystole following the first paroxysms is $0.26 \mathrm{sec}$. and of that following the second paroxysm is $0.47 \mathrm{sec}$. 
which are absolutely constant in contour, and it has a short coupling to the initiating sinus beat which always measures $0.24 \mathrm{sec}$. The first cycle length of all paroxysms is constantly $0.4 \mathrm{sec}$. and the remaining monomorphic ectopics have an invariable cycle length of 0.325 of a second. Usually after two to four intervening sinus beats an identical paroxysm follows. At other times, as in Fig. 12 a longer run of sinus rhythm occurs interrupted by single ventricular ectopics which show widely varying coupling times. The inter-ectopic intervals, however, between the last beat of a paroxysm and these isolated ectopics are precise multiples of $0.325 \mathrm{sec}$., the cycle length of the main body of the paroxysm. A similar time relationship is not demonstrable between the isolated extrasystoles and any part of a paroxysm that follows them. Fig. 12 shows two typical paroxysms demonstrating these time relationships. This is clearly a complex ventricular arrhythmia showing features of both intermittent parasystole (i.e. fixed coupling of the first ectopic beat of a paroxysm to the preceding sinus beat) and also of the ordinary variety of parasystole (i.e. ectopics with widely varying coupling times). The findings, however, strongly suggest that, as in Case 3, the ectopic focus in this patient was capable of automatic impulse formation.

This patient was given quinidine with temporary improvement but died suddenly three days later.

\section{Discussion}

The cases described belong to that variety of paroxysmal tachycardia characterized by short individual paroxysms separated by only a few sinus beats. Lewis may have been the first to describe a case under the title "Single and Successive Extra Systoles" (Lewis, 1909). Gallavardin described both the atrial and ventricular varieties of the condition and was the first to insist on its distinction from classical paroxysmal tachycardia-type Bouveret (Gallavardin, 1922b, and $c$ ). He named the condition "extra systolie à paroxysmes tachycardiques" and later, with Dumas, used the term "tachycardie en salves" (Gallavardin and Dumas, 1924). The ventricular variety appears to be much less common than the atrial. Gallavardin also separated a group in which a similar arrhythmia was precipitated by exertion or emotion for which he used the term "tachycardie paroxystique à centre excitable" (Gallavardin, 1922a). The occurrence of such arrhythmia with or without emotion or exertion as precipitating factors was reported by Wilson et al. (1932) and by Parkinson and Papp (1947). The latter renamed the condition "repetitive paroxysmal tachycardia."

Most authors have regarded the condition as benign (Gallavardin, 1922a, $b$ and $c$; Froment, 1932 and 1953; Parkinson and Papp, 1947). The sudden fatal outcome in Cases 3 and 4 suggests that in the presence of structural heart disease the arrhythmia may be potentially dangerous. It would clearly be of considerable importance to be able to establish the criteria that imply an ominous prognosis in this arrhythmia. If the patient is known to have structural heart disease it would seem wise to regard the condition with apprehension but the presence of such disease may well prove difficult to confirm or exclude. As in Case 1, cardiomegaly may simply be due to the abnormal rhythm and does not necessarily indicate organic heart disease. Some authors have stressed the essential monomorphism of the runs of ectopic beats in cases without underlying heart disease. Case 1, however, clearly demonstrates that this is not a reliable guide and indeed in Case 4, who died suddenly, the ectopic beats showed the most consistently regular contour of the four cases. It is possible that electrocardiographically the most important feature of the two fatal cases was the evidence that the ectopic focus possessed some degree of independent automatism. This would be consistent with the observations that parasystole occurs predominantly in patients with organic heart disease (Scherf and Schott, 1953).

Even in the absence of organic heart disease, it is questionable whether the term "benign" is entirely appropriate for this arrhythmia. Although in general the prognosis is good, many of the reported cases have had disabling symptoms, sometimes with phases of frank heart failure, and some 
have died during prolonged attacks (Elliot and Fern, 1934); others without serious symptoms have died suddenly (Wilson et al., 1932; Maddocks, 1947).

Case 1 is described in detail because it presents the very unusual feature that more than half the paroxysms commence with an ectopic beat of fundamentally different contour from the following beats. The presence of more than one ventricular focus in repetitive ventricular tachycardia appears to be very rare. Wenckebach and Winterberg (1927) described a case with two apparently distinct ventricular ectopic foci. Two successive paroxysms are shown; both are preceded by a single sinus beat and consist of seven ventricular ectopics, the main deflection of the first ectopic having a direction opposite to that of the succeeding six. The observation of Jones and White (1926) seems more consistent with minor variations in conduction of impulses originating in the same focus.

In the present case two apparently unrelated rules were found, which appeared to determine whether a paroxysm would commence with an X or a Y ectopic, namely the "pause rule" and the "C ectopic rule." A partial explanation for the pause rule may lie in the well-known relation between the refractory period of the heart and the preceding cycle length (Scherf and Schott, 1953). The brief refractory period following short pauses would clearly favour the Y ectopic with its shorter coupling whereas the lengthened refractory phase following a long pause may prevent a response from the $Y$ focus and thus permit the $X$ ectopic with its longer coupling to appear. This does not however explain why pauses of intermediate length are followed by two sinus beats and a Y paroxysm for when a $\mathrm{Y}$ complex fails to follow the first sinus beat one would expect that an $\mathrm{X}$ would do so. No explanation can be offered for the consistent suppression by the $\mathrm{C}$ ectopic of the $\mathrm{X}$ variety of ectopic beat.

Two effects of posture on the arrhythmia were noted; if sinus rhythm was present in the supine position, runs of ectopic beats often appeared when the patient stood up. These runs, however, consisted of $\mathrm{Y}$ ectopic beats only, and the $\mathrm{X}$ variety never occurred in the erect position. Postural factors in ectopic arrhythmias are well recognized (Scherf and Schott, 1953; Dutrieux, 1959).

It cannot be claimed that the analysis of this arrhythmia sheds any new light on the underlying mechanism of ectopic impulse formation. Nevertheless, a complex arrhythmia is shown to conform to clear-cut rules and this finding suggests that a statistical approach to long records might well make its own contribution to electrocardiography. Knowledge of the general structure of arrhythmias thus obtained must ultimately be relevant to a full understanding of the underlying physiological disturbance.

\section{SUMMARY}

Four cases of repetitive ventricular tachycardia are described. No evidence of structural heart disease was found in Cases 1 and 2. Case 1 shows the very unusual feature of two distinct ectopic foci. The paroxysms consist predominantly of one variety of ectopic complex, termed "Y", but over half of them are initiated by an ectopic beat of entirely different contour and longer coupling time, termed "X" (X paroxysms). X paroxysms are never preceded by more than one sinus beat, whereas those lacking an initial $X$ are usually preceded by two sinus beats ( $2 Y$ paroxysms) and only a minority by one (1Y paroxysms). The ventricular origin of $Y$ is proved by the occurrence of fusion beats; that of $\mathrm{X}$ is probable though final proof is lacking. Most paroxysms consist of four or five ectopic beats, the range being one to twelve. In paroxysms containing five successive Ys the last ectopic has a longer coupling and different shape, and is termed $\mathbf{C}$.

Detailed study of a record containing 464 paroxysms showed that the mean value for postparoxysmal pauses preceding $\mathrm{X}, 2 \mathrm{Y}$, and $1 \mathrm{Y}$ paroxysms was $0.632,0 \cdot 488$, and 0.21 sec. respectively. Analysis of variance revealed these differences to be statistically highly significant, demonstrating a decisive influence of the length of the post-paroxysmal pause on the pattern of the subsequent paroxysm. On the other hand, paroxysms with a terminal $\mathrm{C}$ were, with a single exception, all followed by $2 \mathrm{Y}$ paroxysms, irrespective of the length of the preceding pause, the $\mathrm{C}$ ectopic suppressing the occurrence of an $\mathrm{X}$ as the initial beat of the subsequent paroxysm. A cyclical variation in the incidence of $\mathrm{C}$ occurred over six-minute periods. 
Evidence is presented that long post-paroxysmal pauses are due to retrograde conduction of the last ectopic beat of the preceding paroxysm.

Follow-up studies have shown that the arrhythmia is gradually subsiding and, as the average number of ectopic beats in each paroxysm has declined, their coupling time has progressively increased.

The arrhythmia in Case 2 was much simpler and there was evidence to suggest that it was a toxic effect from tobacco. In this case a clear inverse relation was found between the number of ectopics in each paroxysm and the number of preceding sinus beats.

In Cases 3 and 4, the arrhythmia occurred in patients with known structural heart disease. In both cases there was some evidence that automatic impulse formation occurred at times in the ectopic foci. Both patients died suddenly.

It is suggested that a statistical approach to long electrocardiographic records may prove fruitful.

It is a pleasure to acknowledge my indebtedness to Dr. A. Schott for his constant advise and helpful criticism. I am indebted to Mr. A. H. Iliffe for the statistical analysis and to Mrs. O. Adams for secretarial help.

\section{REFERENCES}

Berard, A. (1931). Arch. Mal. Caeur, 4, 560.

Dutrieux, P. (1959). Arch. Mal. Caeur, 52, 206.

Elliot, A. R., and Fern, G. K. (1934). Amer. Heart J., 9, 806.

Froment, R. (1932). Thése de Lyon. Masson et Cie edit., Paris.

, Gallavardin, L., and Cahen, P. (1953). Brit. Heart J., 15, 172.

Gallavardin, L. (1922a). Arch. Mal. Caur, 15, 1.

- (1922b). Arch. Mal. Cour, 15, 298.

- (1922c). Arch. Mal. Cour, 15, 774.

Jones, A., and White, P. (1926). Amer. Heart J., 2, 139.

Langendorf, R. (1948). Amer. Heart J., 35, 542.

Lewis, T. (1909). Lancet, 1, 382.

Maddox, K. (1947). Amer. Heart J., 33, 739.

Parkinson, J., and Papp, C. (1947). Brit. Heart J., 32, 241.

Scherf, D., and Scott, A. (1953). Extrasystoles and Allied Arrhythmia. Heinemann, London.

, (1959). Amer. J. Cardiol., 3, 351.

Wenckebach, K. F., and Winterberg, H. (1927). Die unregelmässige Herztätigkeit. Engleman, Leipzig.

Wilson, F. N., Wishart, S. W., Macleod, A. G., and Barker, P. S. (1932). Amer. Heart J., 8, 155. 